\title{
Study on the Daily Exchange Rate Movement Based on the Model of Brownian Motion
}

\author{
Zhou Jianguo ${ }^{1, a}$, Liu Wei ${ }^{1, b}$ \\ ${ }^{1}$ School of Economics and Management, North China Electric Power University, Baoding 071003, \\ China

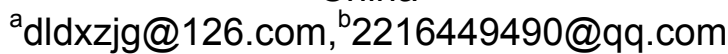

Keywords: Brownian motion; foreign exchange price; empirical study

\begin{abstract}
Theory of Brownian motion is often used to describe the random phenomena of chaos and disorder. This paper tries to make an empirical study on the price of foreign exchange by using theory of Brownian motion. First of all, we use the theory to establish a model to describe the behavior of foreign currency prices. Then the data of the Euro against the US dollar, the Australian dollar against the US dollar and Gold against the US dollar closing price per hour is introduced to simulate the exchange rate by using the model. Finally, we will use the simulated price and the actual price to do a comparative analysis, including the error range, motion direction and inflection point. It was found that the simulation and the actual exchange rate very similar, the results show that this model can be used to forecast.
\end{abstract}

\section{Introduction}

With the rapid development of the foreign exchange market, more and more investors enter into the spot market for speculation. Facing the numerous and complicated movements in the exchange rate, investors only by personal experience is difficult to accurately determine the exchange rate movements to make a correct decision buy or sale. In this paper the exchange rate was simulated by Brown motion model, in order to provide a more scientific basis for decision making for speculators.

Foreign Studies on the Brownian motion is earlier, and widely used in the study of stocks, futures, gold and foreign exchange.In recent years, most people choose to use fractal Brownian theory. K. Ivanova , M. Ausloos ${ }^{[1]}$ used the data for six years to make a empirical analysis of exchange rate movements, it is proved that the exchange rate is more consistent with the multi fractal Brownian motion. S. V. Muniandy, S. C. Lim, R. Murugan ${ }^{[2]}$ used multi fractal Brownian motion model to do a empirical research on the influence of government's intervention policies on the exchange rate in the foreign exchange market in Malaysia. Most of the research on foreign exchange in China is about the structure of foreign exchange investment, investment objects and investment strategies. As for the analysis of the exchange rate trend, Tan Weiping ${ }^{[3]}$ forecasted the trend through technology analysis. Zhang $\mathrm{Yu}^{[4]}$ studied four major exchange rates of China foreign exchange market, found that the exchange rate time series is nonlinear. In the nonlinear system, Liu Xing Quan, Wang Keyu ${ }^{[5]}$ use the fractional Brownian motion model to make empirical study about the US dollar against the yen in New York exchange market, found that estimates of $\mathrm{H}$ index values are in good agreement with the actual exchange rate fluctuations and trends.

Previous studies show that exchange rate is in line with the Brownian motion, the time span of data is always in a few years and most choices is the fractal Brownian motion model. As a global speculative market the foreign exchange market is affected by many factors, investors use day trading to prevent the loss caused by the incident of second day. Therefore, in order to avoid the shortcomings of previous studies in this field we select 24 hours of exchange rate which is more in line with the characteristics of speculative foreign exchange market and more instructive to speculators. Fractal Brownian motion model denies the efficient market hypothesis and developed on the basis of geometric Brownian motion. The research scope of this paper is the closing price per hour of a single day which will rapid and sensitive response to information on the exchange market on the day.It is in line with the efficient market hypothesis that the price reflects all the information 
available. Therefore, this paper selects the geometric Brown motion model which can make this study more practical significance and application value.

\section{The Model of Brownian Motion}

The main factors of foreign exchange fluctuation are upward or downward trend and average volatility, The former depends on the length of time, the latter only depends on the random fluctuations caused by the movement of Brownian. We introduce a model describing the behavior of exchange rate:

$$
d s_{t}=\mu s_{t} d t+\sigma s_{t} d w_{t}
$$

$\mathrm{s}_{\mathrm{t}}$ is the foreign exchange price for $\mathrm{t}, \mathrm{ds}_{\mathrm{t}}$ is the changes in exchange rate, It shall be composed of certain items (expectation) and volatility (random), $\mu$ is the average exchange rate(expected drift rate), $\sigma$ is standard deviation (volatility), $\mathrm{w}_{\mathrm{t}}$ is Standard Brownian motion.

At time intervals $\Delta \mathrm{t}, \Delta \mathrm{w}_{\mathrm{t}} \sim \mathrm{N}(0, \Delta \mathrm{t}), \mathrm{dw}_{\mathrm{t}}=\varepsilon \sqrt{d t}, \varepsilon \sim \mathrm{N}(0,1)$.

According to Ito theorem:

$$
\mathrm{dlns}_{\mathrm{t}}=\left(\mu-\frac{\sigma^{2}}{2}\right) \mathrm{dt}+\sigma \mathrm{dw}_{\mathrm{t}}
$$

That is $\mathrm{dlns}_{\mathrm{t}} \sim \mathrm{N}\left[\left(\mu-\frac{\sigma^{2}}{2}\right) \mathrm{dt}, \sigma^{2} \mathrm{dt}\right]$.

The discrete form of the stochastic differential equation can be expressed as:

$$
\operatorname{lns}_{\mathrm{t}+\Delta \mathrm{t}-}-\operatorname{lns}_{\mathrm{t}}=\left(\mu-\frac{\sigma^{2}}{2}\right) \Delta \mathrm{t}+\sigma \varepsilon \sqrt{\Delta t}
$$

By (2) and (3) can be calculated:

$$
\mu=\sigma^{2}=\frac{\frac{E\left(\ln s_{t+\Delta t}-\ln s_{t}\right)}{\Delta t}+\frac{\sigma^{2}}{2}}{\Delta t}
$$

\section{Empirical Analysis}

According to the different properties of foreign currencies, we select three currencies that are relatively stable and have different characteristics, including the safe haven currency and commodity currency. It can make data more representative. We chose closing prices per hour of the Euro against the US dollar, the Australian dollar against the U.S. dollar and Gold against the U.S. dollar of 24 hours in August 5, 2015. We take $\Delta \mathrm{t}$ is 1 . According to historical data as well as formula (4), (5) calculate $\mu, \sigma$, as table 1 .

Table 1 Estimating Means and Standard Deviations of Three Currencies

\begin{tabular}{cccc}
\hline & EUR / USD & AUD / USD & Gold / USD \\
\hline$\mu$ & 0.00016725985 & -0.00010693263 & -0.000035378392 \\
$\sigma$ & 0.001057341 & 0.001116575 & 0.001212112 \\
\hline
\end{tabular}


We randomly sampled $\varepsilon \sim \mathrm{N}(0,1)$ through Excel, select 24 samples. According to the estimated mean and standard deviation of the various currencies, use the formula (3) to simulate the results, make a comparative analysis between the simulation and the real exchange rate about the maximum value, minimum value, mean, median, kurtosis, skewness and correlation. As table 2,3.

Table 2 Simulated Prices and Real Prices of Three Currency Pairs

\begin{tabular}{|c|c|c|c|c|c|}
\hline Simulated Price1 & Simulated Price2 & Simulated Price3 & Real Price1 & Real Price2 & Real Price3 \\
\hline 1.085999998 & 0.735900000 & 1085.76000 & 1.0860 & 0.7359 & 1085.76 \\
\hline 1.085029122 & 0.734996799 & 1084.40091 & 1.0859 & 0.7361 & 1086.66 \\
\hline 1.084041940 & 0.734082424 & 1083.02385 & 1.0862 & 0.7356 & 1085.71 \\
\hline 1.083665911 & 0.733605446 & 1082.34724 & 1.0867 & 0.7353 & 1086.46 \\
\hline 1.084505319 & 0.733997354 & 1083.06229 & 1.0864 & 0.7354 & 1087.46 \\
\hline 1.084208937 & 0.733577454 & 1082.47700 & 1.0872 & 0.7347 & 1087.61 \\
\hline 1.085655894 & 0.734403047 & 1083.88697 & 1.0864 & 0.7362 & 1085.46 \\
\hline 1.084426165 & 0.733316613 & 1082.23372 & 1.0855 & 0.7366 & 1085.50 \\
\hline 1.085576931 & 0.733930238 & 1083.30420 & 1.0856 & 0.7359 & 1086.06 \\
\hline 1.086333343 & 0.734262023 & 1083.92325 & 1.0869 & 0.7362 & 1087.31 \\
\hline 1.087338451 & 0.734771052 & 1084.82649 & 1.0884 & 0.7370 & 1088.00 \\
\hline 1.086381554 & 0.733880062 & 1083.48592 & 1.0897 & 0.7372 & 1089.36 \\
\hline 1.084940632 & 0.732644381 & 1081.59286 & 1.0876 & 0.7347 & 1084.76 \\
\hline 1.086040492 & 0.733220760 & 1082.60391 & 1.0867 & 0.7344 & 1084.01 \\
\hline 1.087418831 & 0.733995298 & 1083.93284 & 1.0866 & 0.7342 & 1084.21 \\
\hline 1.088423803 & 0.734503330 & 1084.83478 & 1.0872 & 0.7344 & 1085.83 \\
\hline 1.091542525 & 0.736517121 & 1088.15170 & 1.0903 & 0.7353 & 1085.86 \\
\hline Simulated Price1 & Simulated Price2 & Simulated Price3 & Real Price1 & Real Price2 & Real Price3 \\
\hline 1.089245989 & 0.734672440 & 1085.28097 & 1.0898 & 0.7346 & 1084.58 \\
\hline 1.088455730 & 0.733901416 & 1084.13202 & 1.0903 & 0.7354 & 1084.70 \\
\hline 1.087711427 & 0.733163504 & 1083.03609 & 1.0903 & 0.7354 & 1084.49 \\
\hline 1.088632758 & 0.733611245 & 1083.84152 & 1.0898 & 0.7345 & 1084.65 \\
\hline 1.088599715 & 0.733379715 & 1083.55757 & 1.0900 & 0.7352 & 1085.16 \\
\hline 1.087233629 & 0.732200192 & 1081.75310 & 1.0901 & 0.7348 & 1084.90 \\
\hline 1.0882999997 & 0.732750756 & 1082.72345 & 1.0911 & 0.7351 & 1084.10 \\
\hline
\end{tabular}

Note: 1 is EUR/USD, 2 is AUD/USD, 3 is Gold/USD. 
Table 3 Results Statistical Table

Real Price1 Simulated Price1 Real Price2 Simulated Price2 Real Price3 Simulated Price3

\begin{tabular}{ccccccc}
\hline $\begin{array}{c}\text { Maximum } \\
\text { Value }\end{array}$ & 1.0911 & 1.0915 & 0.7372 & 0.7365 & 1089.36 & 1088.15 \\
$\begin{array}{c}\text { Minimum } \\
\text { Value }\end{array}$ & 1.0855 & 1.0837 & 0.7342 & 0.7322 & 1084.01 & 1081.59 \\
Mean & 1.0879 & 1.0867 & 0.7354 & 0.7340 & 1085.78 & 1083.67 \\
Median & 1.0872 & 1.0864 & 0.7354 & 0.7339 & 1085.60 & 1083.52 \\
Kurtosis & -1.6102 & -0.1056 & -0.4299 & 1.2340 & 0.41161 & 2.91313 \\
Skewness & 0.3132 & 0.4599 & 0.5253 & 0.7541 & 0.90160 & 1.29517 \\
Relevance & - & 0.7524 & - & 0.2728 & - & 0.10128 \\
\hline
\end{tabular}

Note: 1 is EUR/USD, 2 is AUD/USD, 3 is Gold/USD.

According to the comparison between simulated price and actual price about the maximum, minimum, mean and median, the simulated price of EUR/USD is very close to the actual price, even only $4 / 10000$ of the gap and the gap about AUD/USD is only within 2/1000. As for Gold/USD because its marked prices are bigger than others, the estimated values show a large gap. The kurtosis of the simulated results of EUR/USD are relatively steady than real prices, the simulated results of AUD/USD and Gold/USD steeper than real prices. The real prices of three currency pairs skew to the right compare with normal distribution and the simulated results skew to the right compare with the real prices.The correlation of EUR/USD between simulation results and real prices is as high as $75 \%$, the correlation of AUD/USD and Gold/USD between simulation results and real prices is relatively low, only $27 \%$ and $10 \%$.

On the whole, simulation results based on Brownian motion are close to the actual prices of closing price in a single day. However, there is still a certain gap, reasons can be attributed to the following aspects: because the analysis basis on the data of the one-day exchange rate, a relatively small number may lead to the simulation results of some inaccuracy; the currency has its own particularity, a country's economic situation and policies have big impact on its currency, some complex factors can not be fully reflected in our model, in particular, both the gold and the U.S. dollar are the safe haven currency.

At the same time, the simulated curve based on Brownian motion can provide more decision-making information for investors. As picture 1,2,3, and table 3 .

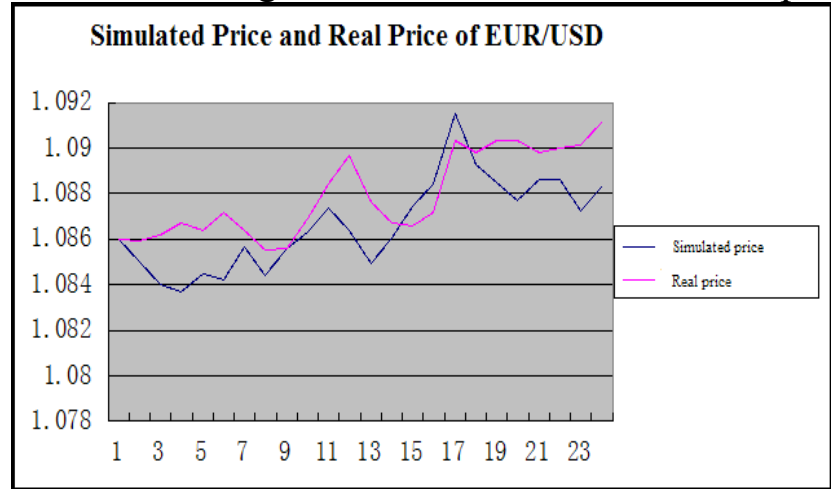

Picture 1 comparison of EUR/USD

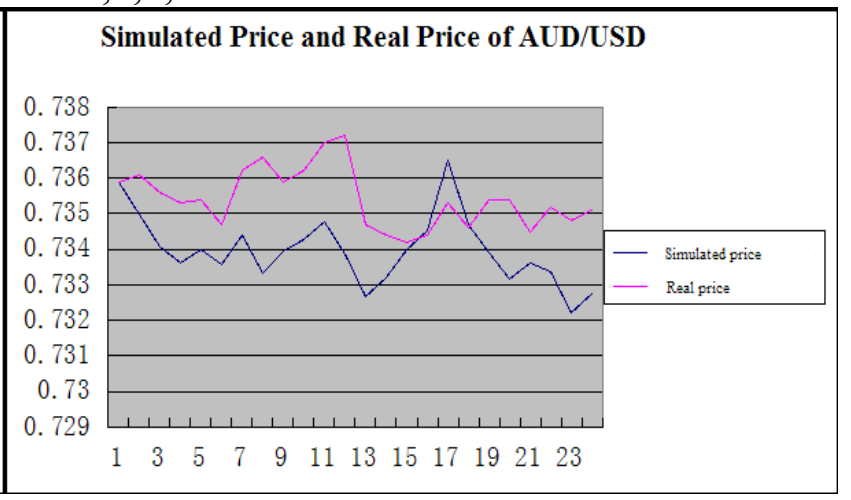

Picture 2 comparison of AUD/USD 


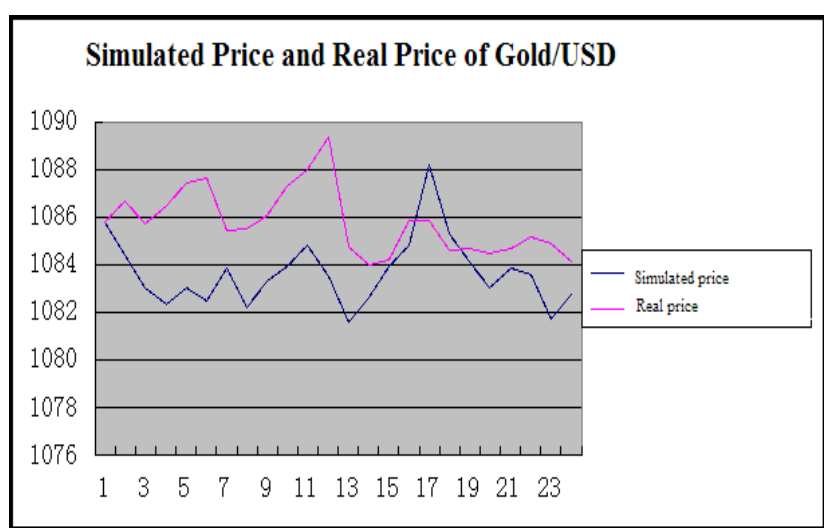

Picture 3 comparison of Gold/USD

Table 3 Peak and Valley of Simulated Price and Real Price

\begin{tabular}{lcccccc}
\hline & \multicolumn{2}{c}{ Advance } & \multicolumn{2}{c}{ Simultaneous } & \multicolumn{2}{c}{ Lag } \\
& Valley & Peak & Valley & Peak & Valley & Peak \\
\hline EUR/USD & 8,13 & & 22 & $1,18 、 21$ & $4,6 、 20$ & 5,7 \\
AUD/USD & 8,13 & $7,11,21,22$ & $4,6 、 20 、 23$ & 5,18 & & \\
Gold/USD & 13,20 & 11 & & 18 & 4 \\
\hline
\end{tabular}

In the table, the advance or simultaneous peak and valley of EUR/USD are more than $60 \%$, as for AUD/USD it reach $100 \%$ and Gold/USD also reach nearly $70 \%$. It is obvious that the most of the peak and valley points are simultaneous even advance, there is a small part of the lag and the points of lag basically appear in the early stages of the simulation.

Therefore, we can combine the simulated prices with the peaks and valleys of simulation which is based on the Brown motion. First we should observe if there are advance or simultaneous points on the simulated curve, it is maybe a clear trading signal, while make sure the simulated price of the exchange rate to achieve which price, then according to the actual price estimate the risk to profit ratio and make a reasonable decision.

\section{Conclusion}

We simulated the exchange rates of three currency pairs of 24 hours according to the model of Brownian motion. Though a comparative analysis between the real price and the simulated price, we find the two price very close. The method of the combination of peak or valley points with the prices has great guiding significance for speculators' trading.Comparing with the previous studies, we take into account the characteristics of the speculative foreign exchange market, select the closing price per hour of 24 hours as the sample and applied to the model of Brownian motion.It provide a objective analytical tool for the speculators to avoid that they can not get sufficient information.

\section{Reference}

[1]S.V. Muniandy,S.C. Lim,R. Murugan. Inhomogeneous scaling behaviors in Malaysian foreign currency exchange rates[J]. Physica A: Statistical Mechanics and its Applications,2001,3011:.

[2]K. Ivanova,M. Ausloos. Low q-moment multifractal analysis of Gold price, Dow Jones Industrial Average and BGL-USD exchange rate[J]. The European Physical Journal B,1999,84:.

[3]Yi Muo. Foreign exchange investment strategy under the warming of risk aversion[J]. Procuratorial Situation,2011,10:96.

[4]Zhang Hong. Foreign exchange investment is about[J]. Conduct financial 
transactions,2011,09:69-70.

[5]Wang Runfang. Foreign exchange investment strategy[J]. Investment in Beijing,2011,10:92.

[6]. Several psychological errors in foreign exchange investment[J]. Chinese trade unions accounting,2010,08:44-45.

[7]Tan Fang, Wang Zongrun. The measurement of the risk of multiple foreign exchange investment portfolio[J]. Statistics and decision making,2010,13:134-138.

[8]Tan Weiping. A study on the spot speculation trading strategy of the euro against the dollar based on trend analysis[D].Hunan University,2013.

[9]Zhang Yu. Empirical Study on exchange rate fluctuations in China's foreign exchange market[D].University of International Business and Economics,2006.

[10]Wang Keyu, Liu Xingquan. The nonlinear system of New York -- exchange rate currencies the dollar / yen exchange rate movements[J]. Quantitative economic technology and economic research, 1997,04:42-43. 